\title{
A review of the complications encountered in a quaternary trauma intensive care unit in South Africa
}

\author{
M Gounder, ${ }^{1,2}$ TC Hardcastle, ${ }^{2}$ DJJ Muckart ${ }^{2}$ \\ 1 Department of Urology, Nelson R. Mandela School of Medicine, University of KwaZulu-Natal, Durban, South Africa \\ 2 Trauma Service, Inkosi Albert Luthuli Central Hospital, Durban, South Africa \& Department of Surgery, University of \\ KwaZulu-Natal, Congella, Durban
}

Corresponding author: Timothy Hardcastle (hardcastle@ukzn.ac.za)

\begin{abstract}
Background: Due to the invasive nature required for support and multiple therapeutic interventions, critically ill patients are at high risk of complications unrelated to their underlying illness or injury. This audit aimed to describe the spectrum of complications in a trauma intensive care unit, to identify potential remedial interventions to improve quality of care and reduce morbidity

Methods: Complications in the Trauma Intensive Care Unit at Inkosi Albert Luthuli Central Hospital are documented prospectively on a specific proforma. A 12-month audit was performed between 2012-2013. Complications were divided into septic and non-septic adverse events and the relationship to injury severity, time of onset and outcome were analysed.

Results: Of 283 patients admitted during the study period, 77 (32.5\%) suffered a total of 161 adverse events. Ninety-seven $(60.2 \%)$ complications were sepsis-related and $64(39.2 \%)$ were unrelated to sespis. Ventilator-associated pneumonia was the commonest septic event (38.1\%) and extubation-related events the most frequent non-septic complication (45.3\%). The number of complications ranged from one in the majority of patients $(49.4 \%)$ to $6(3.9 \%)$ in 3 patients. There was no significant difference in mortality between those with $(24.7 \%)$ or without $(17.4 \%)$ complications $(p=0.22)$ however, those with complications had a significantly longer length of ICU stay $(\mathrm{p}<0.001)$.

Conclusion: Complications are common in the critically injured who necessitate admission to an intensive care unit. The vast majority arise from infective causes, especially ventilator-associated pneumonia. Adverse events related to the endotracheal tube are the commonest non-infective events. The identification of these adverse events should prompt interventions aimed at reducing the incidence.
\end{abstract}

Keywords: trauma intensive care unit, complications, South Africa

S Afr J Surg 2019;57(1)

http://dx.doi.org/10.17159/2078-5151/2019/v57n1a2733

\section{Introduction}

Since the 1990s, the identification and documentation of clinical adverse events, particularly postoperative events and surgical site infection rates after specific procedures, has been advocated as quality indicators in hospital quality assurance programs. ${ }^{1}$ Registering complications is important in surgery, since complications serve as outcome measure and indicators of quality of care..$^{2-4}$ The use of standardised, valid and reliable definitions is fundamental to the accurate measurement and monitoring of surgical adverse events. ${ }^{5}$

Complications in trauma care may occur because of provider-related or patient disease-related events. With regard to provider-related events particularly, errors in technique may be attributed to inexperience, haste, unfamiliarity with devices, inadequate institutional protocols and failure of providers to use recognised endpoints. Furthermore, errors in judgment may occur as a result of failure to access available patient information, proceeding with intervention despite available information, and failure to utilise available care guidelines. ${ }^{6,7}$

Studies of trauma systems have shown that errors in the resuscitative and operative phases occur more commonly, but critical care errors have had the greatest impact on preventable death. Important error patterns included: failure to successfully intubate, secure or protect an airway, delayed operative or angiographic control of acute abdominal/pelvic haemorrhage, delayed intervention for ongoing intrathoracic haemorrhage, inadequate deep vein thrombosis (DVT) or gastrointestinal prophylaxis, lengthy initial operative procedures rather than damage control surgery in unstable patients, over-resuscitation with fluids, and complications of feeding tubes. The most common single error across all phases 
of care was failure to appropriately evaluate the abdomen. ${ }^{8-11}$

Although essential for life support in the critically ill, by its very nature the ICU is a dangerous environment for a patient. The insertion of hollow luminal devices into the upper airway, vascular system, and urinary tract, and the need for multiple drug therapies coupled with limited physiological and immunological reserve invite complications unrelated to the pathology necessitating admission. Few studies have addressed trauma ICU complications in the South African setting, with little to no quantification or categorization of these often preventable errors. In a one-year prospective study by Muckart et al. ${ }^{12}$ just over one-third of patients admitted to a surgical ICU suffered one or more adverse events with a significant increase in mortality. To address this knowledge gap, we reviewed trauma ICU complications among South African patients receiving treatment at a level 1 trauma intensive care unit in a quaternary level hospital in Durban, KwaZulu-Natal, South Africa.

\section{Patients and Methods}

\section{Data Sources}

We conducted a retrospective study at the Trauma Intensive Care Unit (TICU) Inkosi Albert Luthuli Central Hospital (IALCH), a quaternary level teaching hospital located in Durban, KwaZulu-Natal (KZN) and a Trauma Society of South Africa accredited Level 1 Trauma Centre. The unit receives both children and adults directly from the scene of injury or from various regional hospitals within the province of KZN. All complications are recorded on a specific proforma. We reviewed adult and paediatric patients admitted to the TICU from September 2012 to August 2013 and identified those with complications as documented on the proforma. In addition, information was extracted from the hospital electronic records of these patients for the following study objectives:

1. Identify the commonest causes of ICU complications.

2. Categorise and quantify non-sepsis versus sepsis-related complications and recognise significant pathogens.

3. Assess duration of ICU admission and outcome in relation to complications encountered.

Patient data obtained from the electronic registry included demographics, mechanism of injury, length of ICU admission and ventilation, number and type of complications per patient and patient outcome. Complications were categorised into sepsis and non-sepsis related events. Sepsis-related events included surgical site sepsis, pneumonia, vascular catheter related sepsis, urinary tract infection and other sites of sepsis. Non-sepsis related complications were those encountered during insertion or removal of endotracheal tubes, drains, arterial lines, central venous pressure lines, gastric and urinary catheters, as well as resuscitative, intra- or postoperative complications.

\section{Statistical Analysis}

An ICU data collection form was used to collect and manage data. Patients with complications were compared with patients who did not have complications and the chi-square test was used to assess differences in mortality. The means of length of stay for the two groups were compared using a two sample $t$-test assuming unequal variances. All patient variables were analysed using Microsoft Excel 2007 (Microsoft Corporation, Redmond, WA, USA).

\section{Ethical approval}

We obtained ethical approval for the study from the Bioethical Research Ethics Committee of the University of KwaZuluNatal (BE294/13 and BCA207/09). Hospital permission for the use of patient medical records was obtained from IALCH and KZN Department of Health.

\section{Results}

\section{Patient Demographics and Outcome}

Of 238 admissions during the 12-month study period, complications were identified in $77(32.4 \%)$ patients. Sixty two $(80.5 \%)$ out of the 77 patients were male and $15(19.5 \%)$ patients were female. Median age at time of admission was 28 years (interquartile range (IQR) 18-38 years). Seventeen $(22.1 \%)$ out of 77 patients were admitted to the ICU directly from the trauma scene, while $60(77.9 \%)$ were transferred to

\begin{tabular}{ll}
\multicolumn{2}{l}{ Table 1. Patient Demographics and Clinical Data } \\
\hline Age in years median (IQR) & $28(18-38)$ \\
Male $n(\%)$ & $62(80.5 \%)$ \\
Female $n(\%)$ & $15(19.5 \%)$ \\
Inter-hospital transfer $n(\%)$ & $60(77.9 \%)$ \\
Mode of Injury $n(\%)$ & \\
MVA pedestrian & \\
MVA passenger & $25(32.5 \%)$ \\
MVA driver & $15(19.5 \%)$ \\
Gunshot wound & $14(18.2 \%)$ \\
Stab wound & $5(6.5 \%)$ \\
Blunt trauma & $3(3.9 \%)$ \\
Other & $13(16.9 \%)$ \\
Length of ICU stay in days median (IQR) & $2(2.6 \%)$ \\
Ventilatory support $n(\%)$ & $16(11-24)$ \\
Number of complications $n$ (\%) & $71(92.2 \%)$ \\
1 &
\end{tabular}


the ICU from other hospitals. The mechanism and mode of injury are described in Table 1 . The median length of stay in ICU was 16 days (IQR 11-24 days). Seventy one (92.2\%) patients required ventilatory support, with a median duration of 11 days (IQR 8-18 days) per patient. The injury severity score (ISS) was $>16$ in $66(83.1 \%)$ patients, with a median ISS of 29 (IQR 20-34) in the survivor group and 34 (IQR 25-41) in the non-survivor group.

\section{Characteristics of Complications}

Thirty nine $(50.6 \%)$ patients developed 2 or more complications (Table 1). The total number of complications was 161, of which $64(39.8 \%)$ were non sepsis-related (Table 2) and $97(60.2 \%)$ were sepsis-related events (Table 3$)$. The characteristics and frequency of complications, in relation to onset, ISS and mortality, are detailed in Tables 2 and 3.

Of the 64 non-sepsis related complications 29 (45.3\%) were directly related to removal of the endotracheal tube, of which the need for reintubation was the commonest complication. Twelve (18.8\%) adverse events were as a consequence of shock, postoperative haemorrhage and or cardiorespiratory arrest, and $9(14.1 \%)$ complications occurred postprocedurally, 6 of which required further surgical intervention.

With regard to sepsis-related complications, 37 (38.1\%) out of 97 events were due to ventilator associated pneumonia (VAP). The median onset of pneumonia was Day 8 of ICU admission (IQR Day 5-13). The most common organisms found in patients with pneumonia were Haemophilus influenzae, Acinetobacter baumannii, Klebsiella pneumoniae and Pseudomonas aeruginosa observed in 12 (32.4\%), $9(24.3 \%), 8(21.6 \%)$, and $4(10.8 \%)$ of cases respectively. Acinetobacter baumannii, particularly, was isolated with other organism/s in $6(66.7 \%)$ out of 9 pneumonia cases, however $2(33.3 \%)$ out of those 6 cases had a concomitant Acinetobacter baumannii bacteraemia. In $10(27.0 \%)$ of the 37 pneumonia cases, the same organism isolated from the respiratory site was also isolated from non-respiratory site/s up to 7 days after the diagnosis of pneumonia. The median onset of surgical site sepsis was Day 9 of ICU admission (IQR Day 6-16). The most common causative agent of surgical site sepsis, isolated from $5(29.4 \%)$ out of 17 cases, was Pseudomonas aeruginosa. The most common organisms found in other sepsis-related complications, are described in Table 3.

The median length of ICU stay for patients with complications was 16 days (IQR 11-24 days) compared to 7 days (IQR 4-13) in those without complications ( $p<0.001)$. Of the 161 patients without adverse events there were $28(17.4 \%)$ deaths compared to $19(31.6 \%)$ in the 77 patients who incurred complications $(\mathrm{p}=0.22)$.

\section{Discussion}

The highest quality of care is the expected norm in a level 1 trauma ICU; notwithstanding, complications do occur in such settings. Our study describes the characteristics of complications encountered by patients in a South African level 1 trauma ICU over a twelve-month period. We found

Table 2. Spectrum of non sepsis-related complications for trauma cases

\begin{tabular}{|c|c|c|c|c|}
\hline Complication & $\begin{array}{c}\text { Frequency } \\
n(\%)\end{array}$ & $\begin{array}{c}\text { Day of Onset } \\
\text { Median (range) }\end{array}$ & $\begin{array}{c}\text { ISS }>16 \\
n(\%)\end{array}$ & $\begin{array}{c}\text { Mortality } \\
n(\%)\end{array}$ \\
\hline Failed extubation & $13 / 77(16.8 \%)$ & $8(2-33)$ & $12 / 13(92.3 \%)$ & $0 / 13(0.0 \%)$ \\
\hline Post-extubation stridor & 9/77 (11.7\%) & $6(4-26)$ & $8 / 9(88.9 \%)$ & $0 / 9(0.0 \%)$ \\
\hline Shock or cardiorespiratory arrest & $8 / 77(10.4 \%)$ & $1(1-7)$ & $7 / 8(87.5 \%)$ & $6 / 8(75.0 \%)$ \\
\hline Accidental extubation & $7 / 77(9.1 \%)$ & $6(2-21)$ & $6 / 7(85.7 \%)$ & $2 / 7(28.6 \%)$ \\
\hline $\begin{array}{l}\text { Postoperative complication requiring } \\
\text { additional surgery }\end{array}$ & $6 / 77(7.8 \%)$ & $13(1-26)$ & $3 / 6(50.0 \%)$ & $3 / 6(50.0 \%)$ \\
\hline Venous thrombosis/pulmonary embolism & $4 / 77(5.2 \%)$ & $18(7-35)$ & $3 / 4(75.0 \%)$ & $1 / 4(25.0 \%)$ \\
\hline Postoperative haemorrhage & $4 / 77(5.2 \%)$ & $5(2-8)$ & $3 / 4(75.0 \%)$ & $3 / 4(75.0 \%)$ \\
\hline $\begin{array}{l}\text { Arterial Line/Gastric Catheter-related } \\
\text { complication }\end{array}$ & $3 / 77(3.9 \%)$ & $6(1-23)$ & $2 / 3(66.7 \%)$ & $2 / 3(66.7 \%)$ \\
\hline Small bowel obstruction & $3 / 77(3.9 \%)$ & $11(6-34)$ & $1 / 3(33.3 \%)$ & $0 / 3(0.0 \%)$ \\
\hline Pneumothorax & $2 / 77(2.6 \%)$ & $16(1-30)$ & $1 / 2(50.0 \%)$ & $1 / 2(50.0 \%)$ \\
\hline Postoperative myocardial infarction & $1 / 77(1.3 \%)$ & $6^{*}$ & $1 / 1(100 \%)$ & $1 / 1(100 \%)$ \\
\hline Aspiration Pneumonia & $1 / 77(1.3 \%)$ & $4 *$ & $1 / 1(100 \%)$ & $1 / 1(100 \%)$ \\
\hline Wound dehiscence & $1 / 77(1.3 \%)$ & $11 *$ & $0 / 1(0.0 \%)$ & $0 / 1(0.0 \%)$ \\
\hline Adverse drug reaction & $1 / 77(1.3 \%)$ & $5^{*}$ & $1 / 1(100 \%)$ & $0 / 1(0.0 \%)$ \\
\hline Failed intubation & $1 / 77(1.3 \%)$ & $1 *$ & $0 / 1(0.0 \%)$ & $0 / 1(0.0 \%)$ \\
\hline
\end{tabular}

Total

$64^{\dagger}$

ISS = Injury Severity Score; *Range not calculated based on single value; $†$ Several patients developed more than one non sepsis-related complication. 


\begin{tabular}{|c|c|c|c|c|c|c|c|}
\hline \multirow[t]{2}{*}{ Complication } & \multirow{2}{*}{$\begin{array}{c}\text { Frequency } \\
n(\%)\end{array}$} & \multirow{2}{*}{$\begin{array}{l}\text { Day of Onset } \\
\text { Median (IQR) }\end{array}$} & \multirow{2}{*}{$\begin{array}{c}\text { ISS*> } 16 \\
n(\%)\end{array}$} & \multirow{2}{*}{$\begin{array}{c}\text { Mortality } \\
n(\%)\end{array}$} & \multicolumn{3}{|c|}{ Most Common** Organisms Isolated } \\
\hline & & & & & $\begin{array}{c}\text { Acinetobacter } \\
\text { baumannii } \\
n(\%)\end{array}$ & $\begin{array}{c}\text { Klebsiella } \\
\text { pneumoniae } \\
n(\%)\end{array}$ & $\begin{array}{c}\text { Pseudomonas } \\
\text { aeruginosa } \\
n(\%)\end{array}$ \\
\hline Pneumonia & $37 / 77(48.1 \%)$ & $8(5-13)$ & $33 / 37(89.2 \%)$ & $5 / 37(13.5 \%)$ & 9/37 (24.3\%) & $8 / 37(21.6 \%)$ & $4 / 37(10.8 \%)$ \\
\hline Surgical site sepsis & $17 / 77(22.1 \%)$ & $9(6-16)$ & $11 / 17(64.7 \%)$ & $4 / 17(23.5 \%)$ & $3 / 17(17.6 \%)$ & $1 / 17(5.9 \%)$ & $5 / 17(29.4 \%)$ \\
\hline Line sepsis & $15 / 77(19.5 \%)$ & $15(8-21)$ & $9 / 17(52.9 \%)$ & $2 / 15(13.3 \%)$ & $6 / 15(40.0 \%)$ & $2 / 15(13.3 \%)$ & $2 / 15(13.3 \%)$ \\
\hline Bacteraemia & $12 / 77(15.6 \%)$ & $15(10-20)$ & $9 / 12(75.0 \%)$ & $2 / 12(16.7 \%)$ & $4 / 12(33.3 \%)$ & $3 / 12(25.0 \%)$ & - \\
\hline $\begin{array}{l}\text { Urinary tract } \\
\text { infection }\end{array}$ & $7 / 77(9.1 \%)$ & $17(11-40)$ & $4 / 7(57.1 \%)$ & 1/7 (14.3\%) & $2 / 7(28.6 \%)$ & $1 / 7(14.3 \%)$ & $2 / 7(28.6 \%)$ \\
\hline Peritonitis & $4 / 77(5.2 \%)$ & $10^{*}$ & $1 / 4(25.0 \%)$ & $2 / 4(50.0 \%)$ & $1 / 4(25.0 \%)$ & $1 / 4(25.0 \%)$ & - \\
\hline Meningitis & $3 / 77(3.9 \%)$ & $13^{*}$ & $3 / 3(100.0 \%)$ & $1 / 3(33.3 \%)$ & $2 / 3(66.7 \%)$ & $1 / 3(33.3 \%)$ & - \\
\hline Sinusitis & $1 / 77(1.3 \%)$ & $12^{*}$ & $1 / 1(100.0 \%)$ & $0 / 1(0.0 \%)$ & - & $1 / 1(100.0 \%)$ & - \\
\hline Pleural effusion & $1 / 77(1.3 \%)$ & $1^{*}$ & $1 / 1(100.0 \%)$ & $1 / 1(100.0 \%)$ & - & - & - \\
\hline Total & $97^{\dagger}$ & & & & & & \\
\hline
\end{tabular}

that one out of every three patients admitted to the ICU developed complications, comparable to reported ICU complication rates of $22.6-31.2 \%$ in high-income countries (HICs). ${ }^{13,14}$ This is also similar to a previous report from South Africa documenting a complication rate of $34.8 \% .^{12}$ More than ninety percent of patients required ventilatory support during the course of their ICU stay. The need for mechanical ventilation was related to the overall severity of injury, with most patients in our cohort being classified as having serious or severe injury according to their ISS.

The commonest non sepsis-related complications in our study were related to extubation events. The need for invasive mechanical ventilation is associated with airway and pulmonary complications. Hollow luminal devices such as endotracheal tubes have an unfortunate tendency to injure the upper airway, migrate, obstruct, and render patients susceptible to pneumonia. The commonest airway complication was the need for reintubation after planned extubation. Despite the introduction of specific weaning protocols, extubation failure rates have remained static with about one-quarter of patients requiring reintubation. ${ }^{15}$

Numerous pathologies may be attributable to extubation failure including critical illness myoneuropathy, undiagnosed pneumonia, upper airway oedema, and excessive sedation. ${ }^{16}$ The need for reintubation is associated with increased morbidity, and death has been reported in as many as $50 \%$ of those requiring reintubation. ${ }^{17}$ The commonest risk factors are $>60$ years and chronic cardiac or respiratory disease. Although minimising extubation failure, a successful trial of spontaneous breathing is not an absolute guarantee of success and will not identify those suffering upper airway oedema and post-extubation stridor.

The use of steroids in patients at increased risk of postextubation airway oedema prior to extubation has been debatable but recent reviews suggest that a short course is beneficial. ${ }^{18}$ High risk patients include children, neck surgery, eclampsia and neck trauma. While a number of patients with unplanned or accidental extubation who are on a spontaneous breathing mode may not require reintubation, it is a potentially serious complication, especially in those who are undergoing mandatory ventilation. ${ }^{19}$ Frequent assessment of the depth of the endotracheal tube at the incisors, adequate sedation and analgesia, the use of hand restraints, and most importantly counselling awake and cooperative patients are useful interventions.

VAP is the most common nosocomial infection in mechanically ventilated patients, ${ }^{20}$ and was diagnosed in $38 \%$ of our patient cohort and accounted for almost $50 \%$ of sepsis-related complications. Although reported to be commoner in trauma patients, it appears to have less impact on outcome compared to non-trauma critically ill patients. ${ }^{21}$ That the vast majority of trauma patients are much younger than those with non-trauma pathologies explains this paradox. Although a direct association with mortality is debatable, it is associated with prolonged mechanical ventilation, longer ICU stay, increased use of antimicrobials and higher costs. ${ }^{22}$ Time of onset may be defined as early within 48 hours of intubation, or late occurring from Day 5 onward. Early VAP is associated with community acquired and late VAP with hospital acquired pathogens. This is influenced, however, by prior exposure to antimicrobials. ${ }^{23}$ The majority of episodes in our study occurred after 5 days and were therefore late VAPs. Gram-negative organisms were observed in most cases of pneumonia, with Haemophilus influenzae being the most frequently observed organism, and that this was isolated in late VAP is due to most of the patients being antibiotic naïve with no prior therapy.

Surgical site infections are common in the critically ill 
who have undergone abdominal surgery. ${ }^{24}$ The majority of organisms involve hospital acquired ESKAPE pathogens namely Enterococcus faecium, Staphylococcus aureus, Klebsiella pneumoniae, Acinetobacter baumannii, Pseudomonas aeruginosa, and Enterobacter species. In February 2017, the World Health Organisation considered them the greatest threat to health as these pathogens demonstrate considerable resistance to antimicrobials. As such, empiric antimicrobials must cover extended spectrum and possibly carbapenemase beta-lactamase producers.

Although Acinetobacter baumannii was the most frequently observed organism in all our sepsis-related cases, its pathogenic role is debatable and in the majority of instances it is simply a coloniser. To avoid overuse of antimicrobials it is essential that colonization be distinguished from invasive infection. ${ }^{25}$ Antimicrobials may not be necessary, and due to its inherent multi-drug resistance our policy is not to institute treatment if found with other pathogens. ${ }^{26}$ In the presence of sepsis and if Acinetobacter baumannii is the sole isolate, then therapy is commenced as it may be pathogenic. ${ }^{27}$ If regarded as colonization, the incidence of sepsis-related complications may have been overestimated in this study.

A significant risk factor for the development of complications is the length of ICU stay, with more than half of our cohort developing complications after Day 7 of ICU admission. The association with length of stay has been described in other studies. $^{13,14}$ On average, non-sepsis related complications occurred earlier during ICU stay than sepsis-related complications, with the exception of venous thrombosisrelated complications. That complications are associated with an increased length of stay is generally accepted but begs the question whether adverse events prolong stay or whether the severity of illness requires a longer time in ICU which invites more complications. The only previous study documenting adverse events in a surgical ICU in South Africa found a significant association with mortality. ${ }^{12}$ Although the mortality rate in patients incurring complications was almost twice that in those without, we could not demonstrate a similar association. Mathematical significance must not be confused with clinical relevance, however, and may simply be a problem of sample size. ${ }^{28}$ Regardless of statistics, a doubling of mortality rate is of undoubted clinical importance and cause for concern. The complications documented in this study emphasise the need for an evaluation of extubation protocols and infection control procedures to reduce the number of provider-related complications.

\section{Conclusion}

While outlining the spectrum of complications that occurred within a level $1 \mathrm{ICU}$ in a South African setting as compared with a first-world setting, this study highlighted significant preventable provider-related complications.

\section{Declaration:}

None of the authors declare any financial or other conflict of interest and the work was self-funded.

\section{REFERENCES:}

1. Biscione FM. Rates of surgical site infection as a performance measure: Are we ready? World J Gastrointest Surg. 2009;1(1):11-5.

2. Bosma E, Veen EJ, de Jongh MA, Roukema JA. Variable impact of complications in general surgery: a prospective cohort study. Can J Surg. 2012;55(3):163-70.

3. Bosma E, Veen EJ, Roukema JA. Incidence, nature and impact of error in surgery. Br J Surg. 2011;98(11):1654-9. doi: 10.002/ bjs.7594. Epub 27 Jun 2011.

4. Ubbink DT, Visser A, Gouma DJ, Goslings JC. Registration of surgical adverse outcomes: a reliability study in a university hospital. BMJ Open. 2012;2(3):(pii)e000891. doi: 10.1136/ bmjopen-2012

5. Bruce J, Russell EM, Mollison J, Krukowski ZH. The measurement and monitoring of surgical adverse events. Health Technol Assess. 2001;5(22):1-194.

6. Hoyt DB, Hollingsworth-Fridlund P, Winchell RJ, Simons RK, Holbrook T, Fortlage D. Analysis of recurrent process errors leading to provider-related complications on an organized trauma service: directions for care improvement. J Trauma. 1994;36(3):377-84.

7. Hoyt DB, Hollingsworth-Fridlund P, Fortlage D, Davis JW, Mackersie RC. An evaluation of provider-related and diseaserelated morbidity in a level I university trauma service: directions for quality improvement. J Trauma. 1992;33(4):586601 .

8. Davis JW, Hoyt DB, McArdle MS, Mackersie RC, Eastman AB, Virgilio RW, et al. An analysis of errors causing morbidity and mortality in a trauma system: a guide for quality improvement. J Trauma. 1992;32(5):660-5; discussion 5-6.

9. Gruen RL, Jurkovich GJ, McIntyre LK, Foy HM, Maier RV. Patterns of errors contributing to trauma mortality: lessons learned from 2,594 deaths. Ann Surg. 2006;244(3):371-80.

10. Settervall CH, Domingues Cde A, Sousa RM, Nogueira Lde S. Preventable trauma deaths. Rev Saude Publica. 2012;46(2):36775. Epub 3 Feb 2012.

11. Teixeira PG, Inaba K, Hadjizacharia P, Brown C, Salim A, Rhee $\mathrm{P}$, et al. Preventable or potentially preventable mortality at a mature trauma center. J Trauma. 2007;63(6):1338-46; discussion 46-7.

12. Muckart DJJ, Bhagwanjee S, Aitchison JM. Adverse events in the Surgical Intensive Care Unit: a cause of increased mortality. S Afr J Surg. 1994;32(2):69-73.

13. Mondello S, Cantrell A, Italiano D, Fodale V, Mondello P, Ang D. Complications of trauma patients admitted to the ICU in level I academic trauma centers in the United States. BioMed Research International. 3 Jun 2014;2014.

14. Prin M, Li G. Complications and in-hospital mortality in trauma patients treated in intensive care units in the United States, 2013. Injury epidemiology. 2016;3(1):18.

15. Glover S, Glossop A. Managing extubation and the post extubation period in the intensive care unit. Eur Med J Respir. 2017;5:85-9.

16. Kulkarni AP, Agarwal V. Extubation failure in intensive care unit: Predictors and management. Ind J Crit Care Med. 2008;12:1-9.

17. Thille AW, Harrois A, Schortgen F, et al. Outcomes of extubation failure in medical intensive care unit patients. Crit Care Med. 2011;39:2612-8.

18. McAffrey J, Farrell C, Whiting P, et al. Corticosteroids to prevent extubation failure: A systematic review and metaanalysis. Int Care Med. 2009;35:977-86.

19. Penualas O, Frutas-Vivar F, Esteban A. Unplanned extubation 
in the ICU: a marker of quality assurance of mechanical ventilation. Crit Care. 2011;15:128. Available from: http:// ccforum.com/content/15/2/128

20. Kalanuria AA, Zai W, Mirski M. Ventilator-associated pneumonia in the ICU. Crit Care. 2014;18:208. Available from: http://ccforum.com/content/18/2/208

21. Cook A, Norwood S, Berne J. Ventilator associated pneumonia is more common but of less consequence in trauma patients compared with other critically ill patients. J Trauma. 2010;69:1083-91.

22. Kollef $\mathrm{MH}$. Ventilator-associated complications, including infection-related complications. Crit Care Clin. 2013;29:33-50.

23. Ramsamy Y, Muckart DJJ, SweSwe Han K, Mlisana KP. The effect of prior antimicrobial therapy for community acquired infections on the aetiology of early and late ventilator-associated pneumonia in a level I trauma intensive care unit. S Afr J Infect Dis. 2017;32:91-5.

24. Ballus J, Lopez-Delgado JC, Sabater-Riera J, et al. Surgical site infections in critically ill patients with secondary and tertiary peritonitis: epidemiology, microbiology and influence in outcomes. BMC Infect Dis. Epub 30 July 2015. doi: 1186/ s12879-015-1050-5

25. Ramsamy Y, Hardcastle TC, Muckart DJJ. Surviving sepsis in the intensive care unit: The challenge of antimicrobial, resistance and the trauma patient. World J Surg. 2017;41:116569.

26. Ramsamy Y, Muckart DJJ, Bruce JL, et al. Empiric antimicrobial therapy for probable versus directed therapy for possible ventilator-associated pneumonia in critically injured patients. S Afr Med J. 2016;106:196-200.

27. Ntusi NBA, Badri M, Khalfey H, Whitelaw A, Oliver S, Piercy $\mathrm{J}$, et al. ICU-Associated Acinetobacter baumannii Colonisation/ Infection in a High HIV-Prevalence Resource-Poor Setting. PLOS ONE. 2012;7(12):e52452.

28. Luus HG, Muller FO, Meyer BH. Statistical significance versus clinical relevance. S Afr Med J. 1989;76:568-70. 